\title{
Characterisation of mobile genetic elements in Mycoplasma hominis with the description of ICEHo-II, a variant mycoplasma integrative and conjugative element
}

Birgit Henrich $^{1 *}$ (D), Stephanie Hammerlage ${ }^{1}$, Sebastian Scharf ${ }^{1,2}$, Diana Haberhausen ${ }^{1}$, Ursula Fürnkranz ${ }^{3}$, Karl Köhrer ${ }^{4}$, Lena Peitzmann ${ }^{4}$, Pier Luigi Fiori ${ }^{5}$, Joachim Spergser ${ }^{6}$, Klaus Pfeffer ${ }^{1}$ and Alexander T. Dilthey ${ }^{1,7,8}$

\begin{abstract}
Background: Mobile genetic elements are found in genomes throughout the microbial world, mediating genome plasticity and important prokaryotic phenotypes. Even the cell wall-less mycoplasmas, which are known to harbour a minimal set of genes, seem to accumulate mobile genetic elements. In Mycoplasma hominis, a facultative pathogen of the human urogenital tract and an inherently very heterogeneous species, four different MGE-classes had been detected until now: insertion sequence ISMhom-1, prophage MHoV-1, a tetracycline resistance mediating transposon, and ICEHo, a species-specific variant of a mycoplasma integrative and conjugative element encoding a T4SS secretion system (termed MICE).

Results: To characterize the prevalence of these MGEs, genomes of $23 \mathrm{M}$. hominis isolates were assembled using whole genome sequencing and bioinformatically analysed for the presence of mobile genetic elements. In addition to the previously described MGEs, a new ICEHo variant was found, which we designate ICEHo-II. Of 15 ICEHo-II genes, five are common MICE genes; eight are unique to ICEHo-II; and two represent a duplication of a gene also present in ICEHo-I. In $150 \mathrm{M}$. hominis isolates and based on a screening PCR, prevalence of ICEHo-I was 40.7\%; of ICEHo-II, 28.7\%; and of both elements, 15.3\%. Activity of ICEHo-I and -II was demonstrated by detection of circularized extrachromosomal forms of the elements through PCR and subsequent Sanger sequencing.
\end{abstract}

Conclusions: Nanopore sequencing enabled the identification of mobile genetic elements and of ICEHo-II, a novel MICE element of M. hominis, whose phenotypic impact and potential impact on pathogenicity can now be elucidated.

Keywords: Mobile genetic element, Mycoplasma, M. hominis, Nanopore sequencing

\footnotetext{
* Correspondence: birgit.henrich@hhu.de

${ }^{1}$ Institute of Med. Microbiology and Hospital Hygiene of the Heinrich-Heine-University Duesseldorf, Duesseldorf, Germany

Full list of author information is available at the end of the article
}

(c) The Author(s). 2020, corrected publication 2020. Open Access This article is licensed under a Creative Commons Attribution 4.0 International License, which permits use, sharing, adaptation, distribution and reproduction in any medium or format, as long as you give appropriate credit to the original author(s) and the source, provide a link to the Creative Commons licence, and indicate if changes were made. The images or other third party material in this article are included in the article's Creative Commons licence, unless indicated otherwise in a credit line to the material. If material is not included in the article's Creative Commons licence and your intended use is not permitted by statutory regulation or exceeds the permitted use, you will need to obtain permission directly from the copyright holder. To view a copy of this licence, visit http://creativecommons.org/ licenses/by/4.0/. The Creative Commons Public Domain Dedication waiver (http://creativecommons.org/publicdomain/zero/1. 0/) applies to the data made available in this article, unless otherwise stated in a credit line to the data. 


\section{Background}

Mycoplasma hominis is a facultative pathogen of the human urogenital tract and associated with bacterial vaginosis, pelvic inflammatory disease, septic arthritis, preterm birth or even neonatal meningitis [1-3]. The factors accounting for the pathogenic potential of this heterogeneous species with the second smallest genome described so far are not fully understood. Several studies were conducted to characterize host-pathogen interactions in vitro [4-6] and in vivo [7-9], including microarray-based characterization of host [10] and pathogen [11] transcriptome changes in M. hominis infection. With increasing numbers of completely resolved M. hominis genomes (20 at the time of writing; https://www.ncbi.nlm.nih.gov/genome/), however, it became increasingly clear that mobile genetic elements, such as of MhoV-1 [12], ISMhom-1 [13], the tet $(M)$-carrying transposon [14], and the recently detected ICEHo element [15], significantly contribute to genomic plasticity of M. hominis [16].
The present study was conducted to elucidate the presence and prevalence of mobile genetic elements in selected clinical strains of $M$. hominis. To ensure the correct resolution and localization of MGE-associated genomic repeats, a Nanopore-based long-read sequencing approach was combined with an Illumina-based assembly polishing strategy.

\section{Results}

Generation of high-quality assemblies of $11 \mathrm{M}$. hominis strains

A hybrid approach combining short- and long-read sequencing data (Table 1) was used to generate highquality assemblies of 11 isolates of $M$. hominis. Briefly, the Oxford Nanopore and Pacific Biosciences technologies were used to generate $\geq 500 \mathrm{X}$ of long-read sequencing data for each isolate genome; these data were assembled using Canu [17] or HGAP [18] and polished using $\geq 100 \mathrm{X}$ of short-read Illumina sequencing data for each sample. All assemblies were manually inspected for

Table 1 Whole-genome sequencing of 23 M. hominis strains

\begin{tabular}{|c|c|c|c|c|c|c|c|c|}
\hline \multirow[t]{2}{*}{ Strain } & \multicolumn{3}{|c|}{ Short-read sequencing } & \multicolumn{5}{|c|}{ Long-read sequencing } \\
\hline & Protocol & $\begin{array}{l}\text { Generated } \\
\text { data }(\mathrm{Mb})\end{array}$ & Est. coverage (X) & Technology & Kit & $\begin{array}{l}\text { Generated } \\
\text { data (Mb) }\end{array}$ & Est. coverage (X) & $\begin{array}{l}\text { Median read } \\
\text { length/kb }\end{array}$ \\
\hline FBG & $2 \times 300$ & 1612 & 2067 & Nanopore & SQK-RAD003 & 3542 & 4541 & 2.5 \\
\hline 8958 & $2 \times 300$ & 157 & 231 & Nanopore & SQK-RAD003 & 657 & 966 & 4.5 \\
\hline 2539 & $2 \times 300$ & 2344 & 3119 & Nanopore & SQK-LSK108 & 384 & 511 & 12.6 \\
\hline A136 & $2 \times 300$ & 240 & 344 & Nanopore & EXP-NBD103 + SQK-LSK108 & 707 & 1016 & 13.6 \\
\hline SP2565 & $2 \times 300$ & 205 & 287 & Nanopore & & 1092 & 1533 & 10.5 \\
\hline 475 & $2 \times 300$ & 184 & 257 & Nanopore & & 638 & 889 & 5.3 \\
\hline SS10 & $2 \times 300$ & 1648 & 2353 & Nanopore & & 756 & 1080 & 5.7 \\
\hline SS25 & $2 \times 300$ & 1865 & 2772 & Nanopore & & 732 & 1088 & 8.3 \\
\hline VO31120 & $2 \times 250$ & 89 & 130 & Nanopore & & 728 & 1069 & 6.3 \\
\hline SP10291 & $2 \times 250$ & 80 & 106 & Nanopore & & 562 & 749 & 4.4 \\
\hline SP3615 & $2 \times 250$ & 99 & 138 & PacBio & $\begin{array}{l}\text { SMRTbell Template Prep Kit } \\
1.0+\text { Sequel Binding and } \\
\text { Internal Control Kit } 2.1\end{array}$ & 7447 & 10,401 & 2.9 \\
\hline $727 \mathrm{~J}$ & & & & Nanopore & EXP-NBD103 + SQK-LSK108 & 17 & 21 & 5.2 \\
\hline $942 \mathrm{~J}$ & & & & Nanopore & & 38 & 47 & 44.1 \\
\hline 2740 & & & & Nanopore & & 15 & 16 & 4.1 \\
\hline 7388VA & & & & Nanopore & & 39 & 47 & 41.2 \\
\hline 7447VA & & & & Nanopore & & 59 & 66 & 1.7 \\
\hline 10936VA & & & & Nanopore & & 53 & 66 & 3.0 \\
\hline $12256 \mathrm{U}$ & & & & Nanopore & & 35 & 42 & 14.5 \\
\hline 14352VA & & & & Nanopore & & 37 & 47 & 32.3 \\
\hline 16753 & & & & Nanopore & & 7 & 9 & 4.4 \\
\hline 18847 & & & & Nanopore & & 38 & 49 & 45.7 \\
\hline 19791 & & & & Nanopore & & 44 & 52 & 4.6 \\
\hline 21127VA & & & & Nanopore & & 38 & 44 & 42.4 \\
\hline
\end{tabular}


quality. A full description of the sequencing and assembly process is given in the Methods section. Genome lengths of all 11 isolates were larger than that of type strain PG21 (665 kbp [19]), ranging from $673 \mathrm{kbp}$ (SS25) to $780 \mathrm{kbp}$ (FBG); the number of annotated genes, predicted by Prokka [20], ranged from 580 (SS25) to 680 genes (FBG). Two additional publicly available genome sequences were also incorporated into the analysis (TO0613 and PL5).

\section{Detection of mobile genetic elements (MGE) in selected M. hominis strains}

The online software tool Mauve [21] was used for genome alignments (Fig. 1) illustrating homologous regions by colour. Thus, larger isolate-specific regions of gene gain were evident by blocks of zero similarity (e.g. uncoloured sections) and classified as putative mobile genetic elements (MGE).

Four different classes of MGE were characterized in the $M$. hominis genomes: i) insertion sequence ISMhom1 , first described in 2008 [13], ii) prophage MHoV-1
[12], iii) a tetracycline resistance mediating transposon [14], and iv) ICEHo-I and -II, two M. hominis-specific variants of MICE, a mycoplasma integrative and conjugative element [22], of which ICEHo-I corresponds to ICEHo recently published [15]. All MGE insertion sites are shown in Table 2 and visualized in Fig. 1. We detected between 0 (isolates 8958, SS25, and VO31120) and 8 MGEs (isolate FBG) per genome; of note, the three isolates in which no MGEs were detected had the smallest genome sizes.

\section{ISMhom-1}

ISMhom-1 $(1.26 \mathrm{~kb})$ was found in two isolates; isolate SP10291 contained one copy, and isolate FBG carried five copies. ISMhom-1 was highly conserved in sequence, carrying an open reading frame similar to transposase gene tnpA of the IS30 family [13], which was flanked by a nontranslated region (108 bp on the $5^{\prime}$ end

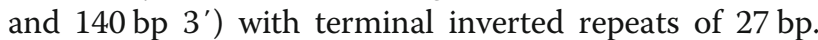
Generation of inverted repeats by IS elements was first described for an IS30-type insertion element of $M$.

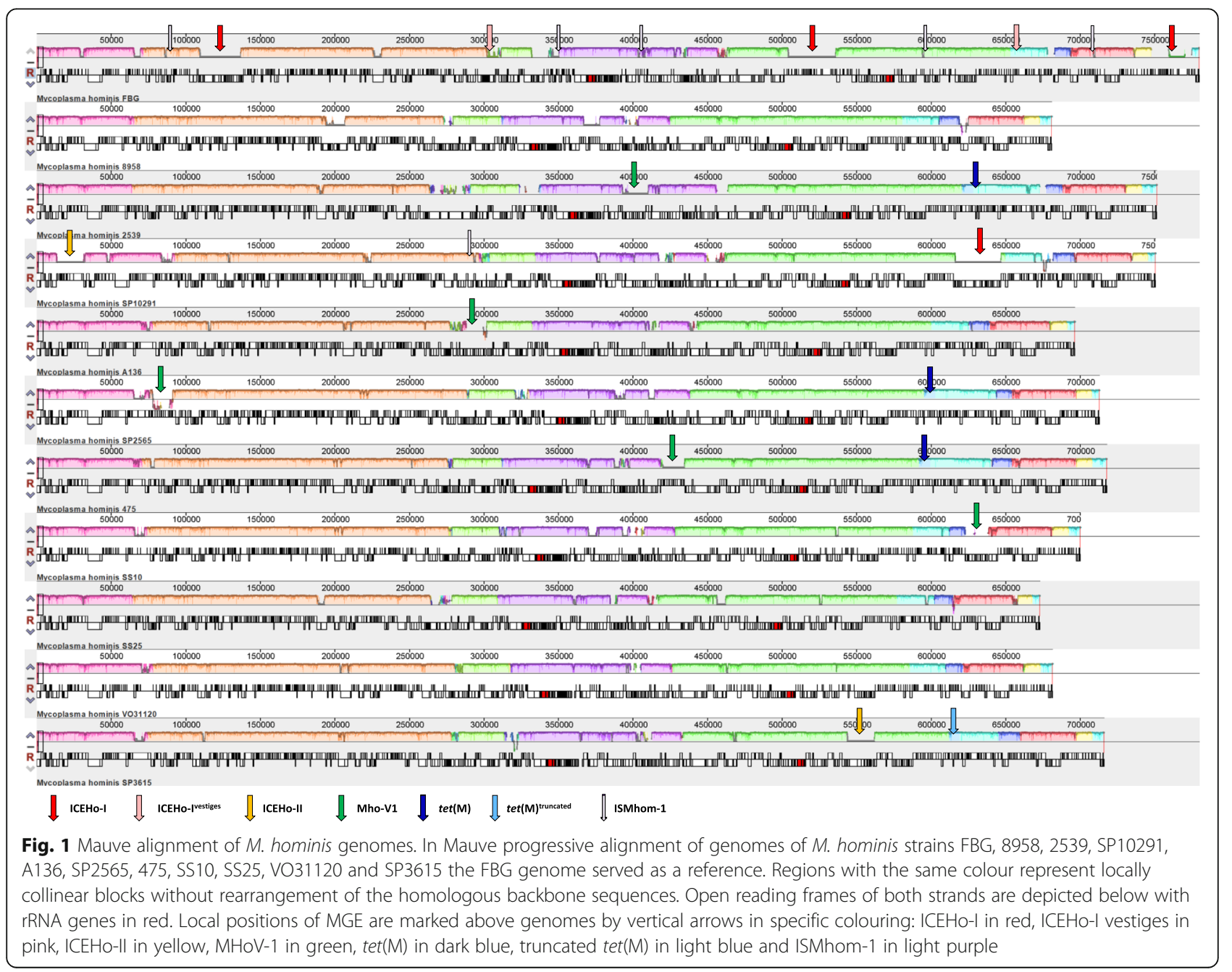


Table 2 Presence and genomic position of mobile genetic elements

\begin{tabular}{|c|c|c|c|c|c|c|}
\hline Strain & $\begin{array}{l}\text { Genome } \\
\text { / bp }\end{array}$ & $\begin{array}{l}\text { ISMhom-1 a } \\
\text { / bp x - bp y }\end{array}$ & $\begin{array}{l}\text { MHoV-1 } \\
\text { /bp x - bp y }\end{array}$ & $\begin{array}{l}\text { tet(M)c } \\
/ \text { bp } \mathrm{x}-\mathrm{bp} y\end{array}$ & $\begin{array}{l}\text { ICEHo-I }{ }^{d} \\
\text { / bp x - bp y }\end{array}$ & $\begin{array}{l}\text { ICEHo-II } \\
\text { / bp x - bp y }\end{array}$ \\
\hline FBG & 780,024 & $\begin{array}{l}85,753-87,012 \\
349,147-350,406 \\
404,580-403,321 \\
593,967-595,226 \\
708,740-709,999\end{array}$ & - & - & $\begin{array}{l}136,576-109,789 \\
508,629-535,415 \\
747,727-774,523 \\
307,652-309385^{f} \\
(675938-675,828)^{g}\end{array}$ & - \\
\hline 8958 & 680,851 & - & - & - & - & - \\
\hline 2539 & 751,326 & - & $407,989-392,742$ & $619,357-644,618$ & - & - \\
\hline SP10291 & 750,518 & $293,110-294,369$ & - & - & $646,629-616,362$ & $13,153-31,485$ \\
\hline A136 & 696,338 & - & $301,276-286,023$ & - & - & - \\
\hline SP2565 & 712,781 & - & $91,014-75,747$ & $593,982-619,248$ & - & - \\
\hline 475 & 717,789 & - & $419,145-434,419$ & $590,550-615,528$ & - & - \\
\hline SS10 & 700,146 & & $637,906-622,632$ & - & - & - \\
\hline SS25 & 672,843 & - & - & - & - & - \\
\hline VO31120 & 681,374 & - & - & - & - & - \\
\hline SP3615 & 715,990 & - & - & $613,432-620,439^{h}$ & - & $543,628-561,978$ \\
\hline TO06613 & 766,228 & - & $694,774-710,019$ & - & $\begin{array}{l}49,522-18,905 \\
310,644-280,027\end{array}$ & - \\
\hline PL5 & $\begin{array}{l}767,767 \\
(J R X A 01)^{j}\end{array}$ & - & - & $74,216-99,476\left(\_000009.1\right)^{\mathbf{j}}$ & $\begin{array}{l}{[89,704-90,264]-[1950-3140]} \\
\left(\_000010.1\right) \mathbf{j}(000001.1) \\
{[1814-1029]-[18,377-17,187]} \\
\left(\_000005.1\right)\left(\_000004.1\right)\end{array}$ & - \\
\hline
\end{tabular}

MGE elements used in BLAST analysis: ${ }^{\text {a }}$ ISMhom-1 (acc.-no. dq973625); ${ }^{\text {b }}$ MHoV-1 prophage region from repB to exiS (acc.- no. CP009652; bp 596,991-bp 581,744); ${ }^{c}$ tet(M) of SPROTT (acc.- no. CP011538; bp 573,817-599,077); ${ }^{d}$ ICEHo-I region of FBG (CDS1 to CDS22, bp 508,629- bp 535,415); ${ }^{\text {e }}$ ICEHo-II region of SP3615 (CDS1 to CDS22, bp 543,628 - bp 561,978); ICEHo-I vestige (corresponding FBG ICEHo-I-2; bp 508,629 - bp 510,361); ${ }^{9}$ ICEHo-I vestige (corresponding to FBG ICEHo-I-2 untranslated region $535,715-535,827) ;{ }^{h}$ truncated tet(M) transposon corresponding to bp 577,017 - bp 584,024 of SPROTT; accession numbers of ${ }^{\mathrm{i}}$ TO0613 genome (acc.-no CP033021.1) and ${ }^{\mathrm{j}}$ PI5 contigs (JRXA01_000001.1 to JRXA01_000010.1)

fermentans [23]. ISMhom-1 insertion positions included un-translated regions (FBG ISMhom-1_1, ISMhom-1_2, ISMhom-1_3, and SP10291) and the 3' ends of the annotated genes BHBFJMJE_00532 and BHBFJMJE_00625 (FBG ISMhom-1_4 and ISMhom-1_5, respectively). The concomitant generation of insertion site-specific inverted repeats resulted in integrity of both ORFs (Table 3).

\section{Prophage MHoV-1}

Prophage MHoV-1 was detected in six isolates (five de novo assembled genomes and one publicly available genome, TO0613). Presence and sequence of genes (from repB to exiS, i.e. spanning the complete $\mathrm{MHoV}-1$ element as defined by [12], and terminated by indirect (IR; AAAGTCCC) repeats of the phage) were highly conserved across the de novo assembled genomes (Table 3). The respective prophage region in TO0613 was structurally consistent with the de novo assembled sequences; several annotated TO0613 genes, however, were disrupted, suggesting a potential assembly problem in the published MiSeq-based assembly of TO0613. No systematic patterns of $\mathrm{MHoV}-1$ integration positions were observed (Table 3). In four cases (strains A136, SP2565, 475 and TO0613), MHoV-1 integrated into intergenic regions; in two cases (strains 2539 and SS10), into open reading frames encoding hypothetical genes of unknown function, leading to premature disruption of the predicted hypothetical genes.

\section{tet(M)-harbouring transposon}

A tet(M)-harbouring transposon of $25 \mathrm{~kb}$ length, mediating tetracycline resistance, was detected in four $M$. hominis strains (2539, 475, SP2565, and PL5). The transposon was highly conserved in gene organisation (see Fig. 2) and sequence ( $>94 \%$ nucleotide identity), and comprised a $13.3 \mathrm{~kb}$ region homologous to transposon Tn916 [14]. Insertion sites of the tet(M)-harbouring transposon were highly conserved, targeting the $3^{\prime}$ end of the rumA gene and leading to RumA C-terminal extension, consistent with findings in strain SPROTT [14], in which a homologous full-length transposon is also present (Fig. 2). Truncated versions of the element were found in strain SP3615 (encompassing conjugative transposon genes but missing integrase gene int), as well as in Ureaplasma urealyticum, serovar 9 (Fig. 2). The functional relevance of these truncations remains unclear. Further BLAST analyses identified a homologous transposon in Parvimonas micra (> 87\% nucleotide identity), 


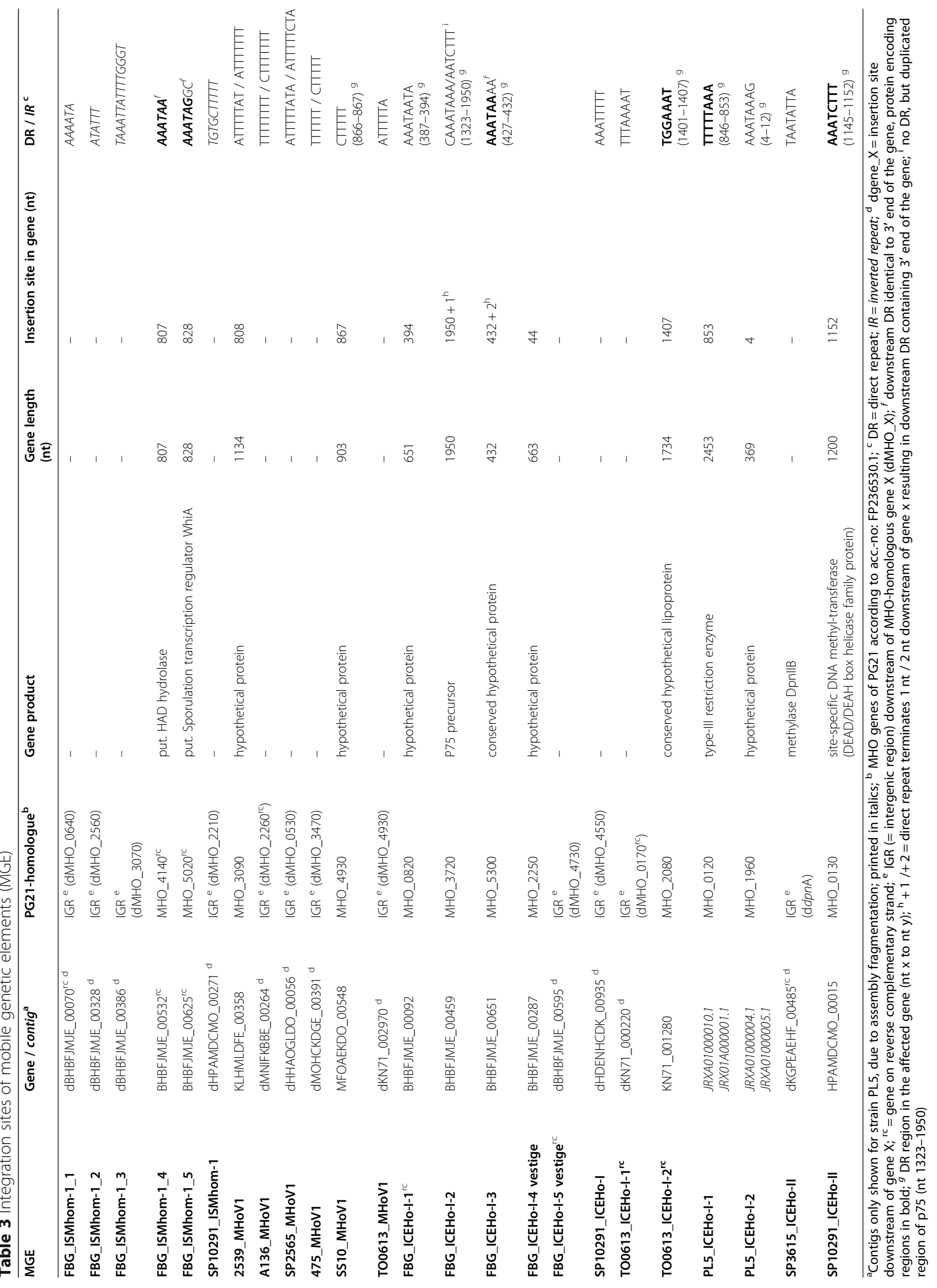




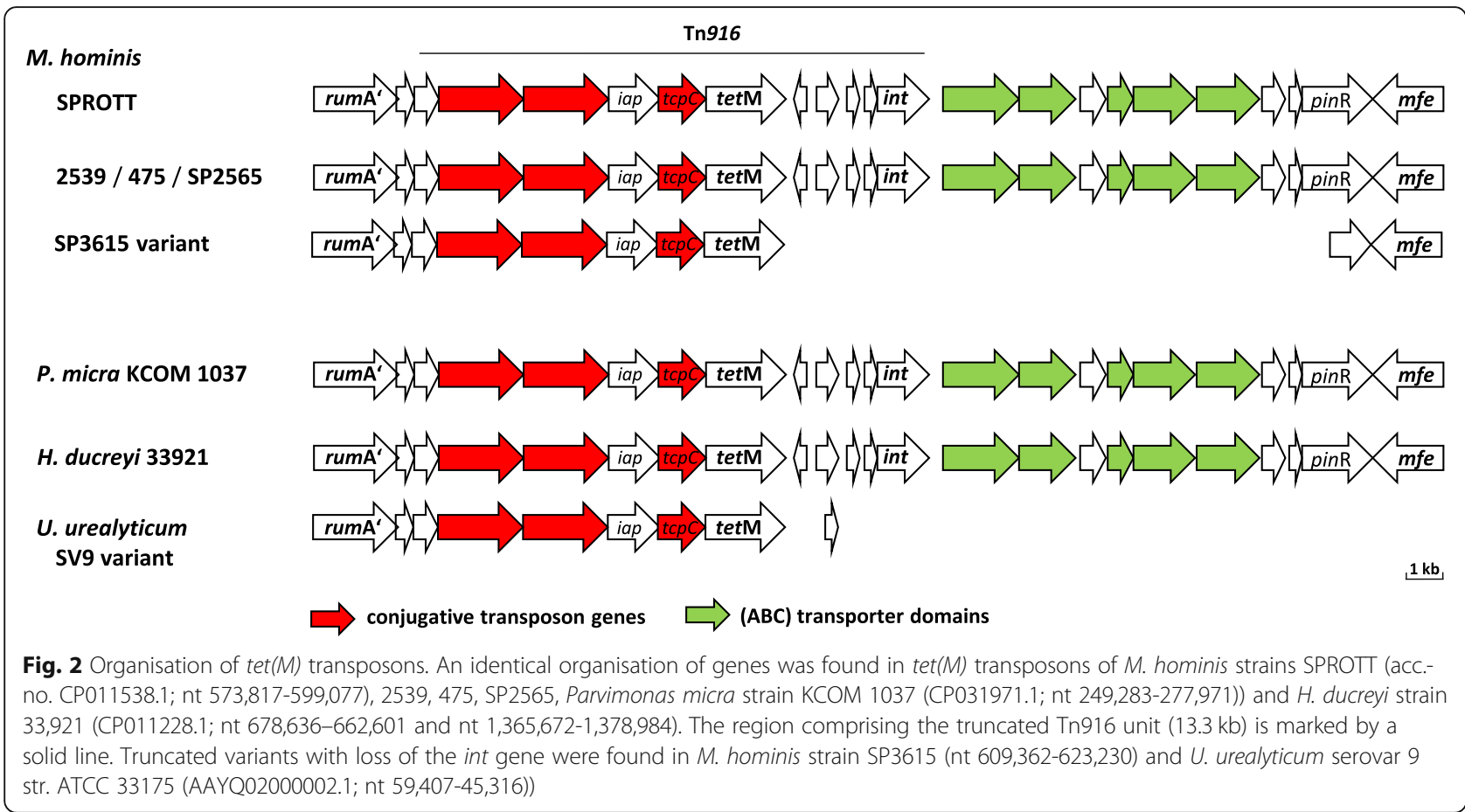

a pathogen which is commonly found in the oral cavity or gastrointestinal tract [24], and two homologous regions in Haemophilus ducreyi strain 33,921 (acc.-no. CP011228.1), covering the entire transposon with $>87 \%$ nucleotide identity.

\section{Mycoplasma integrative and conjugative elements}

Two different MICE variants, ICEHo-I and ICEHo-II, were detected in the $M$. hominis genomes sequenced in this study. The first of these, ICEHo-I, was previously characterized by Meygret el al [15]. and named ICEHo.

\section{Integrative and conjugative element ICEHo-I}

ICEHo-I was detected in four isolate genomes, with copy numbers varying between 1 (SP10291), 2 (strains TO0613 and PL5), and 3 (strain FBG); the genomic locations and features of the integration sites of ICEHo-I are summarized in Tables 2 and 3.

ICEHo-I carried a set of 13 MICE core genes as defined in an analysis of MICE of M. fermentans M64 and M. agalactiae 5632 [22]. MICE core genes exhibited a high degree of conservation across the assembled $M$. hominis genomes; inter-strain homologies of the MICE core proteins ranged from 76 to $100 \%$ with respect to strain FBG (Fig. 3). Inter-species homologies, by contrast, were lower; for example, protein homologies with respect to MICEF-II of $M$. fermentans [22] ranged from $21 \%$ (CDS19) to $58 \%$ (CDS21). Of note, the set of MICE core genes present in ICEHo-I included CDS6. In the original description of ICEHo-I [15], a highly homologous gene
(EVJ69_RS02240 in strain 4788; 100\% amino acid identity) had been classified as a non-core MICE gene [15]; identification with CDS6, however, was justified by $32.3 \%$ amino acid identity and $53.2 \%$ amino acid similarity to ICEFORF6 of $M$. fermentans (Additional file 1).

An analysis of MICE non-core (i.e. cargo) genes in ICEHo-I showed that the genes $d c m$, MhoM, MhoE, and MhoC were always present at a single copy, and their relative position was conserved (Fig. 3). MhoH, MhoG, MhoF, and MhoJ were consistently located between CDS11 and MhoE, and their copy number was variable (ranging from 0 to 1 for MhoG and MhoF; from 0 to 2, for MhoJ; and from 0 and 3, for MhoH). MhoA, MhoK, and MhoL were located between CDS19 and CDS22 and varied in copy number between 0 and 1 (MhoL and MhoK) and 0 and 2 (MhoA). In a phylogenetic analysis of MhoH, MhoJ, and MhoF, MhoF of strain 4788 clustered with $\mathrm{MhoH}$ (Additional file 2), demonstrating that MhoH and MhoF are closely related.

ICEHo-I untranslated regions $(210 \mathrm{bp}$ upstream of CDS1 and $413 \mathrm{bp}$ downstream of CDS22) were highly conserved and terminated by an inverted repeat. ICEHoI integration into host genomes resulted in the generation of direct repeats (Table 3). In two instances, integration was associated with a premature stop of translation, affecting a hypothetical protein (strain FBG; at nucleotide 394/651 of the MHO-0820-homologous BHBFJMJE_00092) and a lipoprotein (strain TO0613; at nucleotide 1407/1734 of the MHO-2080 homologue). In strain PL5, analysis of insertion sites was limited by 


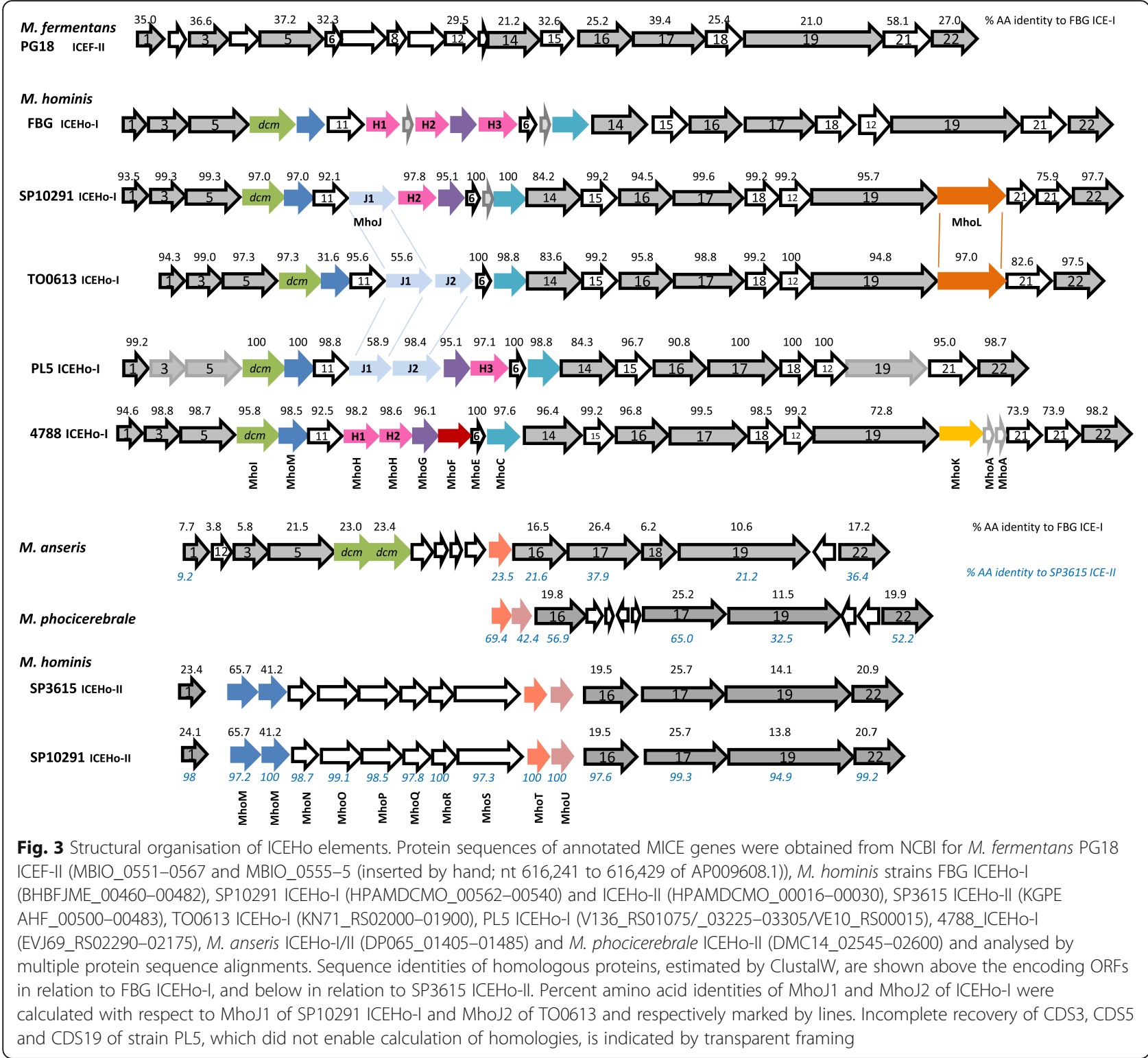

incomplete genome resolution, but BLAST analysis suggested an insertion into the MHO-0120- and MHO1960-homologous genes, putatively encoding a type III restriction enzyme and a hypothetical protein, respectively. In strain FBG, integration of ICEHo-I-2 was associated with a large duplication within the P75 precursor gene resulting in an upstream intact P75-precursor gene (nucleotide 1-1950) and a downstream remnant (nucleotide 1323-1950).

The three complete copies of ICEHo-I in strain FBG exhibited a high degree of conservation and differed by only four nucleotides, associated with a single amino acid exchange in CDS14 of ICEHo-I_3 $\left({ }^{\text {Asn }} 485^{\text {Ile }}\right)$. In addition to three complete copies of ICEHo-I, strain
FBG also harboured two ICEHo-I vestiges (FBG ICEHoI-4 and -5; see Fig. 1 and Table 3).

\section{Integrative and conjugative element ICEHo-II}

The detection of two additional regions of zero similarity with respect to the other $M$. hominis genomes in strains SP3615 and SP10291 (highlighted in Fig. 1) led to the discovery of another mycoplasma integrative and conjugative element, referred to as ICEHo-II. ICEHo-II was conserved in length $(\sim 18 \mathrm{kbp})$ and sequence of 15 open reading frames (Fig. 3; 94.9-100\% AA identity).

Protein homology analyses classified five of the open reading frames as MICE-core genes CDS-1, - 16, - 17, -19 , and -22 , with homologies of the encoded proteins 
to the respective ICEHo-I proteins of FBG-ICEHo-I ranging from $14.1 \%$ (CDS19) to $25.7 \%$ (CDS17). Of the ICEHo-II cargo gene encoded proteins (MhoM to MhoU), only protein MhoM, duplicated in ICEHo-II, was also found in ICEHo-I with $30-50 \%$ AA identity. A phylogenetic analysis showed that MhoM generally clustered distinctly from CDS11 into ICEHo-I- or -II-specific branches; except for ICEHo-I MhoM protein of TO0613, which was phylogenetically positioned between ICEHo-II MhoM and CDS11 (Additional file 3).

ICEHo-II untranslated regions (207 bp upstream of CDS1 and 210 bp downstream of CDS 22) were terminated by inverted repeats (IRL: GGCCGTGTAAAAAA TATAAGGAAT and IRR: ATTCCTTTAATAATAAAC ACGACC). In strain SP10291, ICEHo-II insertion led to a premature stop in the MHO-0130-homologous gene, putatively encoding a site-specific DNA methyltransferase belonging to the DEAD/DEAH box helicase family (see Table 3). In strain SP3615, ICEHo-II was reversely inserted between the MHO-4180- and MHO-4190homologous genes, and three additional genes (KGPEAE HF_0485 to KGPEAEHF_0483) were detected between MHO_4180 and ICEHo-II. A Phyre ${ }^{2}$ analysis of these genes showed homologies to two methyltransferases (KGPEAEHF_0485 and KGPEAEHF_0486) and a $S$. pneumoniae endonuclease encoded in the DpnII gene cassette (KGPEAEHF_0483).

A BLAST analysis identified ICEHo-II-homologous regions in other mycoplasma species, $M$. phocicerebrale [25] and M. anseris [26] (Fig. 3). In the seal pathogen $M$. phocicerebrale a truncated ICEHo-II region was detected, extending from gene MhoT to CDS22. In the duck and goose pathogen $M$. anseris a hybrid ICEHo element was found, carrying the ICEHo-I- homologous MICE genes CDS3, $-5,-12,-18$, and $d c m$, and the ICEHo-II homologous MICE genes CDS1, - 16, - 17, $19,-22$, and MhoT, suggesting a common ancestor or a product of recombination of both ICEHo elements.

\section{Prevalence of ICEHo-I and ICEHo-II elements}

Using a Real time PCR (qPCR) screening approach targeting ICEHo-I and -II-specific small gene fragments, 150 isolates from the $M$. hominis strain collection of our institute were tested for the presence of ICEHo elements (see Methods). For ICEHo-I, 57.3\% of the M. hominis strains $(86 / 150)$ were rated as unambiguously ICEHo-Inegative, and $28 \%(42 / 150)$ were classified as unambiguously ICEHo-I-positive. Of the remaining 22 isolates with ambiguous ICEHo-I-specific probe detection results, 19 isolates were rated as ICEHo-I positive, yielding an overall ICEHo-I detection rate of 40.7\% (61/150). For ICEHo-II, $28.7 \%$ of the $M$. hominis strains (43/150) were tested ICEHo-II-positive; including 15.3\% strains (23/ 150) also positive for ICEHo-I.
To verify the accuracy of the qPCR screen, additional Nanopore long-read sequencing data were generated on 12 isolates (Table 1), draft de novo assembly was carried out, and ICEHo-I and -II positions in the de novo assemblies were determined. ICEHo detection results and genomic locations in the draft de novo assembled genomes are summarized in Additional file 4. The determined ICEHo-I and -II copy number counts agreed with the screening-based results for each evaluated isolate, confirming the accuracy of the qPCR screen. Variability in ICEHo-I structure, as already observed in the set of genomes assembled to high quality, was also found in the newly sequenced isolates; by contrast, the structure of ICEHo-II was found to be highly conserved (Additional file 4).

\section{MGE co-occurrence analysis}

MGE copy numbers were tabulated across the assembled genomes (Table 4) and statistical tests were carried out to assess the evidence for non-random co-occurrence of different MGEs, using the Chi-Square test to detect associations at the level of presence and absence and Spearman's rank correlation test to detect associations at the level of MGE multiplicity. No statistically significant association at $p=0.05$ was found between the presence or multiplicity of ICEHo-II in a given strain and presence of any other MGE; the lowest $p$-values were achieved for MhoV-1 being present more often in the absence of ICEHo-I $(p=0.066)$ and ISMhom-1 only occurring when ICEHo-I was present $(p=0.096)$.

\section{Episomal occurrence of ICEHo elements}

Nanopore reads of the 23 sequenced $M$. hominis strains were mapped to circularized ICEHo-I (strains FBG and SP10291) and ICEHo-II (SP3615 and SP10291). Reads overlapping the IRR-IRL junction site were only detected in strains FBG (ICEHo-I) and 19791 (ICEHo-II). To detect the presence of episomal ICEHo-I and ICEHo-II with increased sensitivity, a Real time PCR assay, designed to exclusively amplify episomal circularized ICEHo (cICEHo), was employed (see Methods). Application of this cICEHo screening assay to 80 ICEHopositive isolates from our collection showed that more than two thirds (49/60) of the ICEHo-I- and more than half $(27 / 43)$ of the ICEHo-II-carrying strains harbour episomal circularized versions of ICEHo-I and -II, respectively (see Additional file 5).

In all whole-genome-sequenced samples, the coupling region $(\mathrm{CR})$ of the episomal ICEs was characterized with Sanger sequencing. In all cases except for cICEHo-I of strain 19791, the detected cICEHO-I and CICEHo-II CR sequences had a length of 6 nucleotides (Fig. 4). The CR of cICEHo-I in strain 19791 consisted of a mixture of six- and eight-nucleotide sequences (ATGAGT and ATATGAGT), with the longer version dominating (see Methods). 
Table 4 MGE copy number in assembled M. hominis genomes

\begin{tabular}{|c|c|c|c|c|c|}
\hline Isolate & ISMhom $1^{\mathrm{a}}$ & MhoV1 $^{\mathrm{b}}$ & tet(M) transposon ${ }^{c}$ & ICEHo- $^{d}$ & ICEHo-II $^{\mathrm{e}}$ \\
\hline FBG & 5 & 0 & 0 & 3 & 0 \\
\hline 8958 & 0 & 0 & 0 & 0 & 0 \\
\hline 2539 & 0 & 1 & 1 & 0 & 0 \\
\hline SP10291 & 1 & 0 & 0 & 1 & 1 \\
\hline A136 & 0 & 1 & 0 & 0 & 0 \\
\hline SP2565 & 0 & 1 & 1 & 0 & 0 \\
\hline 475 & 0 & 1 & 1 & 0 & 0 \\
\hline SS10 & 0 & 1 & 0 & 0 & 0 \\
\hline SS25 & 0 & 0 & 0 & 0 & 0 \\
\hline VO31120 & 0 & 0 & 0 & 0 & 0 \\
\hline SP3615 & 0 & 0 & 1 & 0 & 1 \\
\hline T00613 & 0 & 1 & 0 & 2 & 0 \\
\hline PL5 & 0 & 0 & 1 & 2 & 0 \\
\hline 18847 & 0 & 0 & 0 & 1 & 0 \\
\hline 21127 & 0 & 0 & 1 & 3 & 0 \\
\hline 7388 & 0 & 1 & 1 & 0 & 0 \\
\hline 727 J & 0 & 0 & 0 & 0 & 1 \\
\hline 7447VA & 0 & 1 & 0 & 0 & 1 \\
\hline 2740 & 0 & 1 & 0 & 0 & 2 \\
\hline 16753 & 0 & 1 & 1 & 0 & 2 \\
\hline $942 \mathrm{~J}$ & 0 & 1 & 0 & 1 & 1 \\
\hline 10936 & 0 & 0 & 1 & 1 & 1 \\
\hline 12256 & 0 & 0 & 0 & 1 & 2 \\
\hline 14352 & 0 & 0 & 0 & 1 & 1 \\
\hline 19791 & 0 & 1 & 1 & 1 & 2 \\
\hline
\end{tabular}

MGEs were detected using pairwise sequence alignments between the assembly and MGE query sequences ${ }^{a}$ ISMhom-1, query sequence acc.-no. dq973625, detection threshold: $>80 \%$ identity; ${ }^{b}$ MHoV-1 prophage, query sequences CP009652:581744-584,733 (covering repB) and CP009652:596991-598,991 (covering exiS), detection threshold: $>80 \%$ identity for both query sequences; ${ }^{c}$ tet(M), query sequence CP011538: 573817-599,077 (truncated tet(M) transposon, query sequence CP011538:577017-584,024) (derived from SPROTT), detection threshold: > 80\% identity:i ${ }^{\text {I }}$ ICEHo-l, query sequences: 14 MICE core genes of FBG,

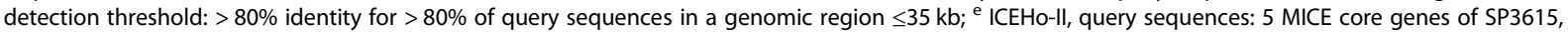
detection threshold: $>80 \%$ identity for $>80 \%$ of query sequences in a genomic region $\leq 20 \mathrm{~kb}$

CR sequences were characterized by a dominance of weak nucleotides $(\mathrm{W}=\mathrm{A}$ or $\mathrm{T})$ and generally corresponded to the genomic sequences of the IRR-/IRL-flanking direct repeats. The CR of circularized ICEHo-I was typically composed of nucleotides $1-6$ of the DR $(n=11)$, less often of nucleotides $3-8(n=4)$ or $1-8(n=1)$. The CR of circularized ICHo-II, by contrast, was typically composed of nucleotides $3-8$ of the DR $(n=7)$, less often of nucleotides $1-6$ $(\mathrm{n}=4)$ or $2-7(\mathrm{n}=1)$.

The detection of major and minor CR sequence variants may reflect (i) simultaneous usage of different DR subregions from the same ICEHo element (see underlined sequence regions of DR in Fig. 4.C), (ii) simultaneous observation of multiple ICEHo-I/-II elements with different DR sequences (ICEHo-II of strain $12256 \mathrm{U}$ ), (iii) circularisation- or recombination-associated mutagenesis in the circularized ICEHo product, (iv) sequencing error. Of note, minor CR sequence variants were also observed in isolates in which only one ICEHo copy was present (e.g. ICEHo-II of SP10291), and we observed mismatches between CR and the underlying genomic DR sequences in both high quality and draft de novo assembled genomes (e.g. AAAAAA in ICEHo-I of FBG, TTTTGTT in ICEHoI of $14352 \mathrm{VA}$, and TTTTTT ICEHo-II of 16753). Of note, joint analysis of $C R$ and DR sequences enabled the mapping of circularized ICEHo copies to their respective genomic origins in strains FBG (for ICEHo-I_1 and 3), 21127 (ICEHo-I_2), 19791 (ICEHo-II_2), and 2740 (ICEHo-II_1). In strain 16753, both copies of ICEHo-II were found in circularized form.

\section{Discussion}

Mobile genetic elements play an important role in mediating prokaryotic genome plasticity, often contributing 


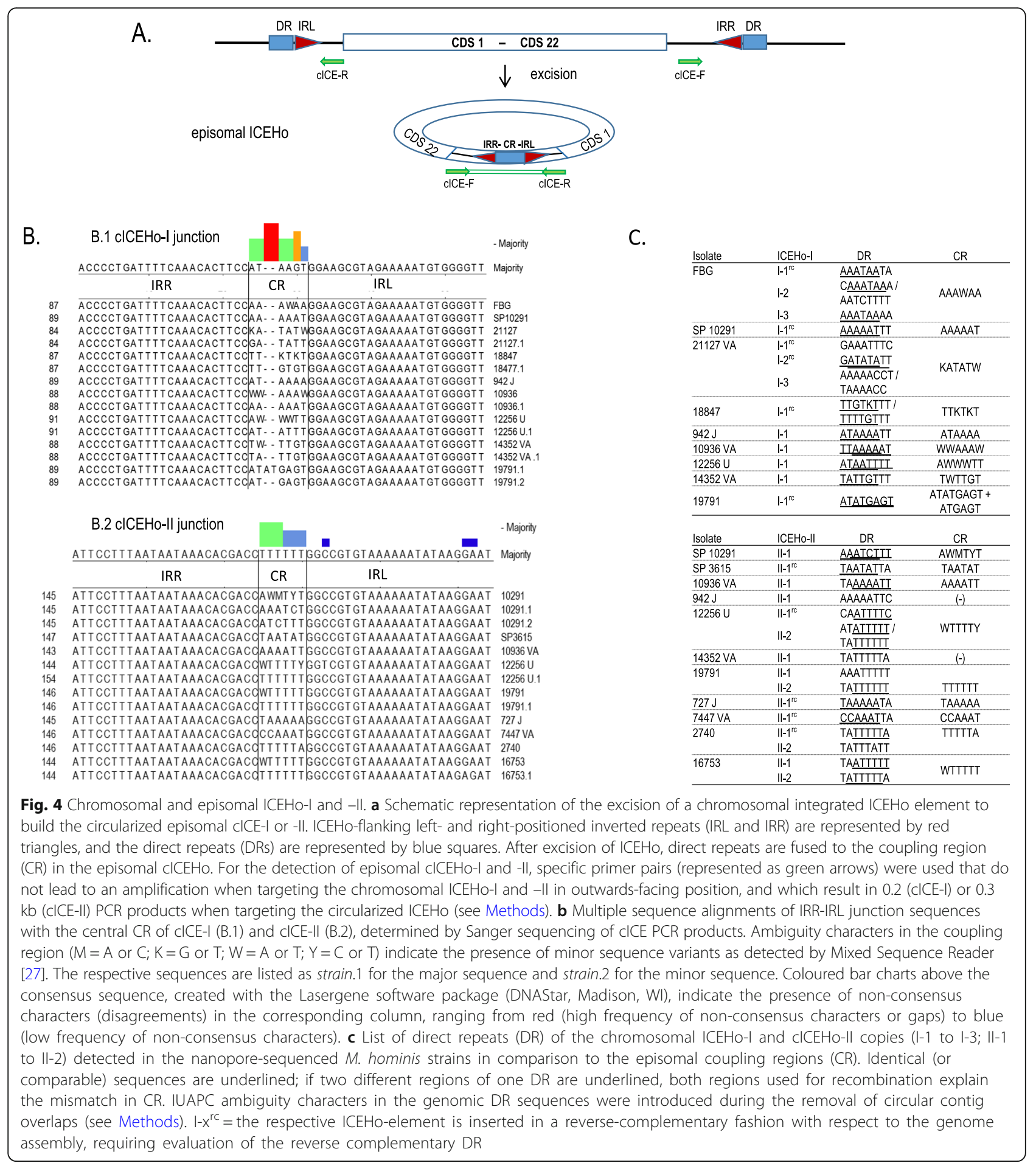

to important phenotypes such as virulence and antibiotic resistance. MGEs can exert their effect by expanding the gene set of the host, or via the disruption of existing genes in the case of integration events. In the present study, we detected and characterized four types of MGEs in clinical isolates of $M$. hominis: ISMhom-1, an insertion sequence; prophage $\mathrm{MHoV}-1$; a tet $(\mathrm{M})$-carrying transposon; and ICEHo-I and -II, two M. hominis-specific integrative and conjugative elements.

\section{MGE insertion patterns}

In our study, ISMhom-1 was found exclusively in noncoding chromosomal regions; in other studies, IS element insertions are also reported in MICEs [28] or MICE 
vestiges [29]. The other types of MGEs detected here were also found to be inserted in coding regions; 2 of 7 detected $\mathrm{MhoV}-1$ insertions led to the interruption of a gene; 6 of 10 ICEHo-I insertion events; and 1 of 2 ICEHo-II insertion events. In more than half of the 11 $M$. hominis genomes assembled to high quality, a chromosomal gene was found to be disrupted by insertion of an MGE. No statistically significant effects were identified during the MGE co-occurrence analysis; the conjecture that ICEHo-I-free isolates may be less susceptible to the entry of other mobile elements [15] was not replicated here.

\section{ICEHo-I and -II gene content}

Horizontal transfer of ICEs from one host to the other is mediated by type IV secretion systems (T4SS), typically comprising the surface-localized pilus, the integral membrane core channel, a protein complex at the cytoplasmic site of the membrane, and ATPases at the cytoplasmic site of the channel [30]. In addition, mobilization and integration of ICEs typically require the presence of a relaxase or integrase enzyme. Genes that participate in the mobilization or conjugation process are referred to as core genes, whereas cargo genes often encode ICE-associated phenotypes of interest, such as resistance [14], metabolic traits [31], or virulence [32]. Characterization of ICEs in mycoplasmas (MICE) has enabled the definition of a MICE core gene set [22], including a mycoplasmaminimized T4SS [22]. ICEHo-II contains a smaller set of MICE core genes than ICEHo-I, but the impact of this on the transfer potential of ICEHo-II remains to be studied. Table 5 shows results of a bioinformatics analysis of putative gene functions, and an integrated view of putative MICE gene functions incorporating results from the literature is shown in Additional file 6. Low levels of homology present significant challenges for the in silico characterization of MICE genes; follow-up experimental studies will be necessary to better characterize the functions of ICEHo-I and -II genes.

\section{Circularization is likely indicative of ICEHo-I and -II transfer potential}

For ICEs, excision and circularization represent key steps in the mobilization process [33]. We used a specifically developed PCR assay to demonstrate the presence of ICEHo-I and -II in their episomal circularized forms across many isolates in our screened cohort. The detection of circularized ICEHo-I and -II demonstrates the first step in the potential horizontal transfer of these elements and indicates that ICEHo-I and -II likely retain their mobile potential. Interestingly, we also detected the presence of minor sequence variants in the coupling region of circularized ICEHo-I and -II elements that could not readily be explained based on the respective genomic
DR regions. Follow-up studies to confirm the existence of these minor $C R$ sequence variants and to characterize their potential functional are an important direction for future work.

\section{Conclusions}

Nanopore sequencing enabled the characterization of mobile genetic elements and the identification of ICEHo-II, a novel MICE element of M. hominis. Our characterization provides a starting point for the elucidation of the function of the ICEHo-I and -II cargo genes and their phenotypic impact, in particular with respect to a potential impact on the pathogenicity of this genetically heterogeneous human facultative pathogen.

\section{Methods}

M. hominis strains

$M$. hominis strains were isolated from human specimens. Strains FBG, 8958 and 2539 were part of a collection of clinical $M$. hominis strains, created at the Institute of Pathology of the Johannes Gutenberg University Mainz, Germany, and transferred in 1988 to the Institute of Med. Microbiology and Hospital Hygiene at the Medical Faculty of the Heinrich-Heine-University of Duesseldorf; strains 475 and A136 derived from the Institute of Microbiology, University of Veterinary Medicine Vienna, Austria; strains SS10 and SS25 from the Institute for Specific Prophylaxis and Tropical Medicine, Centre for Pathophysiology, Immunology and Infectiology, Medical University of Vienna, Austria; and strains SP3615, VO31120, SP10291 and SP2656 were part of the strain collection of our institute, collected within the last 10 years. FBG, 8958 and 2539 were isolated from women; only for isolate 8958, the donor's age (64) and strain location (vaginal) are known. Strain 475 was isolated from vaginal specimen; A136 and SP3615 were isolated from placenta after preterm birth; VO31120 was isolated from pleura of a patient with pneumonia; SP10291 was isolated from brain material after cerebral infarction; SP2565 was derived from blood culture of a patient in NHL remission [34]; SS10 and SS25 were isolated from in vitro cultured $T$. vaginalis (as endosymbionts). Protozoa were isolated from women affected by acute trichomoniasis respectively in 1996 and 1999, at the Department of Biomedical Sciences, University of Sassari, Italy [35]. All other M. hominis strains were taken from the strain collection of our institute in Duesseldorf, lacking information about associated diseases.

\section{M. hominis culturing and genomic DNA preparations}

$M$. hominis strains were cultivated in arginine-medium as described in detail previously [36]. Genomic DNA of the strains was isolated by the use of the QIAamp Blood and Tissue kit (Hilden, Germany) following the tissue 


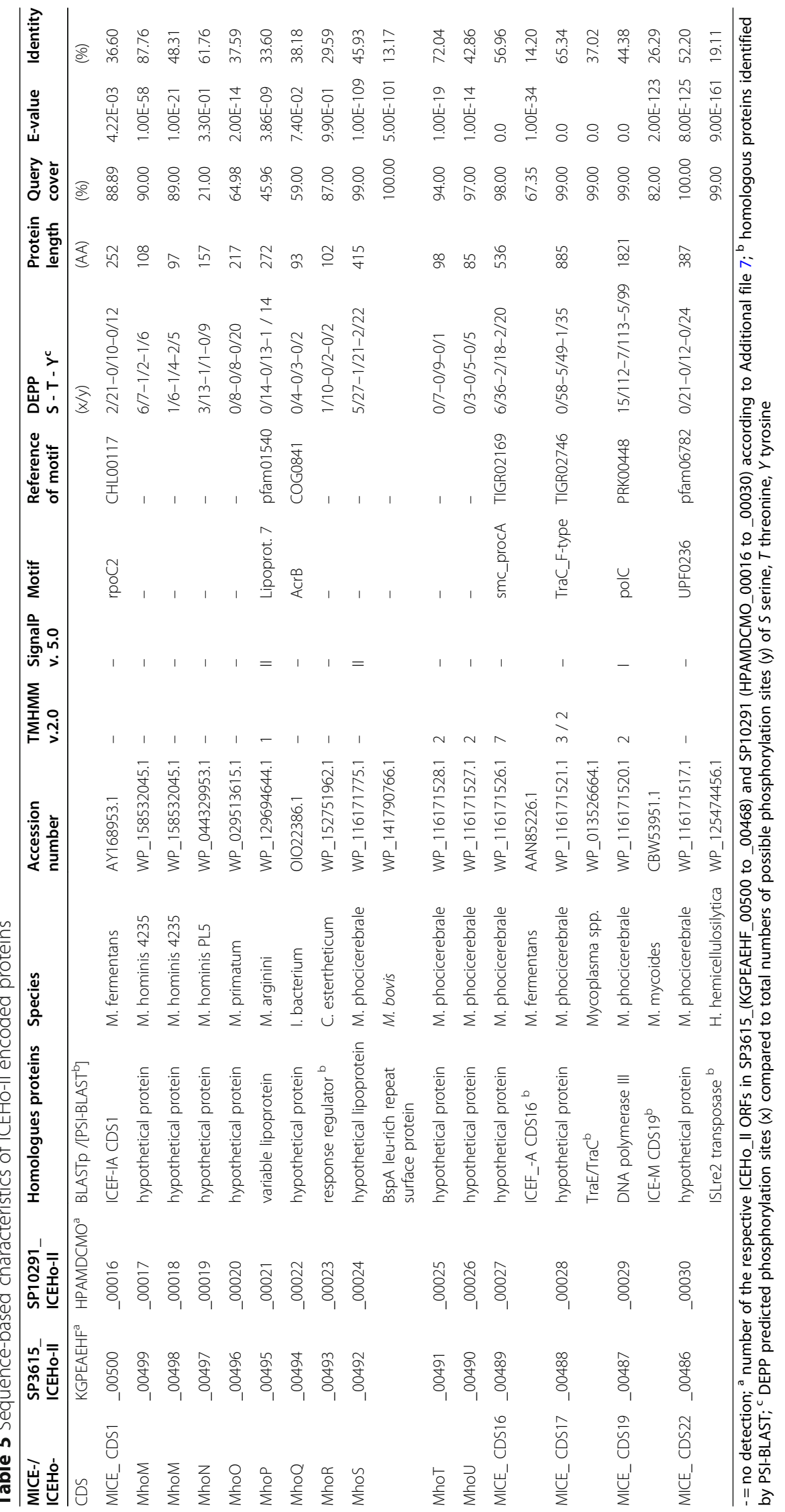


protocol with minor modifications as published [37]. Concentration of genomic DNA was measured by Invitrogen Qubit 4 Fluorometer Qubit and its quality verified spectrophotometrically by NanoDrop 1000 Spectrophotometer and on a Fragment Analyzer System (Agilent, Santa Clara, CA USA) with method DNF-464-33 for high sensitivity large fragment $50 \mathrm{~kb}$ analysis.

\section{Whole genome sequencing and assembly of $M$. hominis strains \\ Generation of short-read sequencing data}

Short-read Illumina sequencing was carried out for 11 isolates. Sequencing libraries were prepared according to the manufacturer's instructions and sequenced on the MiSeq platform with $2 \times 300$ bp or $2 \times 250$ bp paired-end sequencing protocols (Table 1 ).

\section{Nanopore sequencing and assembly}

22 M. hominis strains were sequenced on a MinION MK1B device. Sequencing libraries from quality-controlled genomic DNA were prepared according to the manufacturer's instructions, employing the rapid (2 samples), ligationbased (1 sample), and barcoded ligation-based (19 samples) protocols (Table 1). Basecalling and demultiplexing were carried out with MinKNOW (basecalling only) and Albacore (basecalling and demultiplexing).

Canu [17] 1.6 (with parameters -genomeSize $=1 \mathrm{~m}$ -nanopore-raw) was used for the assembly of the generated long-read data, yielding one large contig for each sample but one. Two smaller contigs in the assemblies of samples SS25 and SP2565 had only spurious read support as reported by Canu and were removed from the assembly. To generate "high quality" assemblies for the samples for which short-read data were available, the assemblies of the first 10 samples (Table 1) were polished with Nanopolish [38] 0.8.4, circular overlaps at the ends of contigs were removed, and orientation to the PG21 type strain genome was carried out. Two rounds of Pilon [39] 1.22 were used for further polishing based on short reads for each of the "high-quality" assemblies. Finally, short-read data were aligned against the Pilon-polished assemblies; GATK [40] 3.7 (with parameters - T HaplotypeCaller -ploidy 1) was used to call variants; and reference alleles were substituted with variant alleles whenever the reference allele frequency, measured via samtools mpileup -q0 -Q10 [41], was $\leq 10 \%$. All shortread alignments were generated with bwa mem [42] 0.7.15-r1140. The genome structure of the generated assemblies was examined with nucmer [43] and the effectiveness of the polishing strategy was assessed by visually screening for potential base errors in IGV [44]. For the remaining 12 samples for which no short-read data were available, Nanopore-only based assemblies (referred to as "draft assemblies") as produced by Canu were only used to characterize the MGEs contain within them. Draft genomes were oriented to the PG21 type strain and the circular contig overlap region was substituted with a consensus sequence of the two underlying overlaps, computed with SeqMan Version 6.0 (DNASTAR. Madison, WI). Of note, ambiguities in the computed consensus were represented using IUPAC ambiguity characters.

To further improve sequence quality for a triplicate repeat (later identified as ICEHo-I) identified by our inspection strategy in the genome of sample FBG, we applied a modification of the GATK-based polishing strategy described above. First, all short reads aligned to any of the three copies of the repeat in the genome of sample FBG were extracted. Second, for the three assembled repeat sequences independently, the complete set of extracted reads was aligned against the individual instance of the repeat and variants were called with GATK (using -ploidy 3). Finally, reference alleles were substituted with variant alleles at homozygous variant positions with reference allele frequency $\leq 10 \%$. A manuscript describing a generalization of our approach and presenting a stand-alone software implementation is currently under preparation.

\section{PacBio sequencing and assembly}

Library preparation for long-read sequencing of $M$. hominis isolate SP3615 on the Sequel system was carried out with the SMRTbell Template Prep Kit 1.0 and the Sequel Binding and Internal Control Kit 2.1, using the "Greater than 10kb Template Protocol" and $10 \mathrm{~h}$ movie time. Assembly was carried out with HGAP4 (SMRT Link Version 5.1.0.26412) [18] and polished with Arrow. Orientation and removal of circular overlaps were carried out as described above,. Visual inspection was used to confirm the quality of the generated assembly.

\section{qPCR}

Oligonucleotides used in qPCRs were designed using Probefinder (Roche Applied Science) (https://qpcr.probefinder.com). Primers are listed in Table 6.

qPCR assays were carried out in a total volume of $25 \mu \mathrm{l}$ consisting of $1 \times$ MesaGreen MasterMix, $5 \mathrm{mM}$ $\mathrm{MgCl}_{2}$, Amperase, $300 \mathrm{nM}$ of each primer and $2.5 \mu \mathrm{l}$ of genomic DNA or cDNA solution, which was derived from $20 \mathrm{ng}$ RNA. Thermal cycling conditions were as follows: 1 cycle at $50^{\circ} \mathrm{C}$ for $10 \mathrm{~min}, 1$ cycle at $95^{\circ} \mathrm{C}$ for 5 min followed by 45 cycles of $95^{\circ} \mathrm{C}$ for $15 \mathrm{~s}$ and $60^{\circ} \mathrm{C}$ for $1 \mathrm{~min}$ (protocol 1) or 1 cycle at $95^{\circ} \mathrm{C}$ for $5 \mathrm{~min}$ followed by 35 cycles of $95^{\circ} \mathrm{C}$ for $15 \mathrm{~s}, 30 \mathrm{~s} 55^{\circ} \mathrm{C}$ and $60^{\circ} \mathrm{C}$ for 45 $\mathrm{s}$ (protocol 2). The product was than heated from $65^{\circ} \mathrm{C}$ to $95^{\circ} \mathrm{C}$ with an increment of $0.5^{\circ} \mathrm{C} / 15 \mathrm{~s}$ and the plate read for melt curve analysis to check the identity of the amplicon. Each sample was analysed in duplicate. 
Table 6 Primers used

\begin{tabular}{|c|c|c|c|c|}
\hline Gene & qPCR primer & Sequence $\left(5^{\prime}-3^{\prime}\right)$ & Amplicon length (nt) & PCR protocol \\
\hline \multirow[t]{2}{*}{ ICEHo-I_dcm } & 463_F & CACGGATCTCCTTGTCAAGAT & & \\
\hline & 463_R & TGTTTCCCACAATAAACTACTTCG & 91 & 1 \\
\hline \multirow[t]{2}{*}{ ICEHo-I_CDS5 } & 462_F & AGAAGATTTGTCAAAAACTCCTAAAGA & & \\
\hline & 462_R & ACCACTTTGTGCTTCGGCTAA & 64 & 1 \\
\hline \multirow[t]{2}{*}{ ICEHo-I_CDS14 } & 474_F & CCAAATCCTTCAAACCCAACT & & \\
\hline & 474_R & TCTGGTTAACTTCAGGGGTTG & 62 & 1 \\
\hline \multirow[t]{2}{*}{ ICEHo-I_CDS16 } & 476_F & GCAATTGCTTTTGTTGGAAGT & & \\
\hline & 476_R & CTGATCTTGCTCCAGACATAGC & 73 & 1 \\
\hline \multirow[t]{2}{*}{ ICEHo-I_CDS17.1 } & 477_F1 & GATTTGTGCCGTCATCGTA & & \\
\hline & 477_R1 & TITAAAATGGCAGGATTATCAGG & 67 & 1 \\
\hline \multirow[t]{2}{*}{ ICEHo-I_CDS17.2 } & 477_F2 & RAAAATATTTGCAAGAACATAACATTA & & \\
\hline & 477_R2 & ATTTCTAACCGTTITGTCATTT & 165 & 1 \\
\hline \multirow[t]{2}{*}{ ICEHo-II_CDS17 } & $17-I I F$ & CCCAATAAATCCGATAGCATTA & & \\
\hline & $17-I I R$ & GTTCCCAACACTAACATTCCTC & 84 & 1 \\
\hline \multirow[t]{2}{*}{ circular ICEHo-I } & CICE_I-F & GCGGGCGCGTAGAGCAT & & \\
\hline & CICE_I-R & TATTTGGAATTAACCCCACATTTT & 185 & 2 \\
\hline \multirow[t]{2}{*}{ circular ICEHo-II } & CICE_II-F & CAAAATTCAGATTAATTACTAATAAACAAA & & \\
\hline & ClCE_II-R & AGAGCATGAGCAAGAAAAAAAGTA & 290 & 2 \\
\hline \multirow[t]{2}{*}{ hitA } & hitA_F & TTGAGGCACAGCAATAGC & & \\
\hline & hitA_R & AAGGCTTAGGTAAGGAATTGATTAG & 81 & 1 \\
\hline \multirow[t]{2}{*}{ gap } & gap_F & GCAGGCTCAATATTTGACTCACT & & \\
\hline & gap_R & GATGATTCATTGTCGTATCATGC & 95 & 1 \\
\hline
\end{tabular}

Cycling, fluorescent data collection and analysis were carried out on a CFX-Cycler of BioRad Laboratories (Munich, Germany) according to the manufacturer's instructions.

\section{ICEHo qPCR screening assay}

Real time PCR (qPCR) was used to screen for the presence of ICEHo-I and -II. For ICEHo-I, qPCR was used to determine the presence of MICE core genes CDS5, $14,-16,-17$, and of the ICEHo-I specific $d c m$ gene. For ICEHo-II, qPCR was used to determine the presence of a conserved region of the ICEHo-II CDS17 gene. Utilized primers are listed in Table 6 . Ct values were interpreted relative to the chromosomal $M$. hominis-specific hitA gene $[45,46]$ (see Additional file 5), with $\Delta \mathrm{Ct}$ values (defined as Ct (ICEHo gene $\mathrm{X}$ ) $-\mathrm{Ct}($ hitA) $) \geq 10$ classified as negative, and $\Delta \mathrm{Ct}$-values $<10$ classified as positive. The utilized $\Delta \mathrm{Ct}$ value threshold of 10 was determined based on strains FBG (ICEHo-I), SP13615 (ICEHo-II), and SP10291 (ICEHo-I and -II) as positive controls, and ICEHo-free strains PG21, 8958, 2539, SP2565, SS10, and VO31120 as negative controls. For ICEHo-I, isolates in which all PCRs were positive were classified as unambiguously positive; isolates in which at least two PCRs were positive were classified as positive; and isolates in which 0 or 1 PCRs were positive were classified as negative. With the chosen threshold values and decision algorithm, assembly- and qPCR-based results were in perfect agreement for the sequenced strains (Additional file 5).

qPCR screening for episomal circularized ICEHo (cICEHo) Real time PCR (qPCR) was used to screen for the presence of ICEHo-I and -II in their episomal circularized forms, utilizing outwards-facing primer pairs (cICE_IF/_I-R and cICE_II-F/_II-R; see Table 6). For ICEHo-I, these primers targeted the conserved untranslated ICEHo-I regions 266 bp downstream of CDS22 (cICE_IF) and $175 \mathrm{bp}$ upstream of CDS1 (cICE_I-R), leading to PCR products of $0.2 \mathrm{~kb}$ in case of episomal circularisation. For ICEHo-II, they targeted the conserved untranslated ICEHo-II regions just downstream of CDS22 (cICE_II-F) and $152 \mathrm{bp}$ upstream of CDS1, leading to cICE-II PCR products of $0.3 \mathrm{~kb}$ in case of episomal circularisation (see Fig. 4.A). In the whole-genomesequenced samples, all cICE amplification products were sequenced with Sanger sequencing, confirming cICE detection results through the detection of a valid IRR-IRL junction and coupling region (CR) in all but two cases with high qPCR Ct values (33 and 31; Additional file 5). 
At higher cycle counts (>30), SybrGreen-based qPCRs are known to be prone to false-positives due to the generation of primer dimers or mispriming to imperfect binding sites. For the wider cohort of samples that were only screened with qPCR, all cICE-PCRs with Ct values $>30$ were thus classified as negative, unless Sanger sequencing of the PCR product proved the presence of a $\mathrm{CR}$ region in the amplification product (Additional file 5). Major and minor CR sequence variants were detected by applying the algorithm Mixed Sequence Reader [27] to the Sanger chromatogram data.

\section{Annotation and bioinformatic analysis of $M$. hominis genomes}

Prokka [20] was used to annotate the assembled genomes. PHAST (PHAge Search Tool) (http://phast. wishartlab.com/) was used to identify and annotate prophage sequences [47]. BLAST Microbes (https://BLAST. ncbi.nlm.nih.gov/BLAST.cgi) was used for detection of homologous genes and plasmids. Multiple sequence alignments were calculated by using Genious Pro (vers. 5.5.8) and MegAlign version 6.0 of the Lasergene software package (DNAStar, Madison, WI). Genome alignments illustrating gene gain, loss and rearrangement were done with Mauve [21]. The Phyre2 web portal was used for protein modelling, prediction and analysis [48]; RADAR for detection and alignment of repeats in protein sequences ( [49] https://www.ebi.ac.uk/Tools/services/web_radar/toolform.ebi); MEME for discovering novel, ungapped motifs (recurring, fixed-length patterns) ( [50] http://meme-suite.org/tools/meme); Disorder Enhanced Phosphorylation Predictor (DEPP) (http://www. pondr.com/cgi-bin/depp.cgi).

\section{Statistical programs used}

Statistical tests were performed in Stata 14 (StataCorp, TX). Associations of presence of different MGEs were assessed by Chi-square test, associations of abundance by Spearman's rank correlation.

\section{Supplementary Information}

The online version contains supplementary material available at https://doi. org/10.1186/s13100-020-00225-9.

Additional file 1. Homology of CDS6. Deduced protein sequences of CDS6 derived from M. hominis strains FBG (BHBFJMJE_00471), SP10291 (HDENHCDK_00553), TO0613 (WP_036439043.1), PL5 (WP_036439043.1), and 4788 (WP 036439043.1) and of M. fermentans strains M64 (ADV34390.1 (I) and ADV34456.1(II)) and PG18 (ICEF-IA (AAN85216.1 (IA)) and ICEF-II-A (AAN85259.1 (II-A)). Two chromosomal proteins of M. hominis PG21 (MHO_0070 (CAX37141.1) and MHO_1280 (CAX37262.1)) were used as unrelated ICE-outliners in ClustalW-based Multiple Sequence Alignment. A. Phylogenetic tree; B. Percent amino acid identities and divergences; and C. Multiple Sequence Alignment of CDS6 encoded proteins. Identical amino acids are marked in green, isofunctional amino acids marked in yellow.
Additional file 2. Clustering of $\mathrm{MhoH}$ and $\mathrm{MhoJ}$. MhoH and Mho proteins of FBG, SP10291, PL5 and TO0613 were clustered in multiple sequence alignment using Clustal $\mathrm{W}$ and divided in five subgroups (MhoH1 to MhoH3 and MhoJ1 and MhoJ2) according to their phylogenetic relationship (A.). All $\mathrm{MhoH}$ and MhoJ proteins carried the TAL-effector motif in the C-terminal part (B.). Percent amino acid identities and divergences are shown in C.).

Additional file 3. Phylogeny of MhoM and CDS11. MhoM encoded proteins of ICEHo-I and -II elements of strains FBG, SP10291, PL5, 4788 and T00613 were clustered with the respective CDS11 genes in multiple sequence alignment using Clustal W. A.) Phylogenetic tree of MhoM and CDS11 encoded proteins. B.) Percent identities and divergences of MhoM and CDS11 proteins.

Additional file 4. ICEHo locations in draft genomes. Positions and gene presence patterns of ICEHo-I and - II in draft de novo assemblies of $12 \mathrm{M}$. hominis strains sequenced only with Nanopore. ICEHo positions in the draft assemblies were determined by aligning the sequences of ICEHo-I of strain FBG and of ICEHo-II of strain SP3615 to the draft assemblies. The additional columns show the homology (nucleotide identity \%) between the genes present in the draft assembly ICEHo elements and the genes present in ICEHo-I of FBG and the genes present in ICEHo-II of SP3615 (gene order and names correspond to Fig. 3).

Additional file 5. qPCR data of ICEHo and CICE. Ct and $\triangle \mathrm{Ct}$ values for ICEHo-I, - II and CICE detection, as well as ICEHo-I and -II status based on the assembled genomes, and confirmatory detection of CICE by Sanger sequencing.

Additional file 6. ICEHo-I and ICEHo-II putative gene functions. ICEHo-I and -II putative gene functions, based on bioinformatics analyses (see main text) and literature review.

Additional file 7. M. hominis genomes in GB.

\section{Abbreviations}

CDS: CoDing sequence; CR: Coupling Region; DEPP: Disorder enhanced phosphorylation predictor; DR: Direct repeat; ICE: Integrative and conjugative element; ICEHo: Integrative and conjugative element of $M$. hominis; MICE: Mycoplasmal integrative and conjugative element; MGE: Mobile genetic element; MTase: Methyltransferase; PHAST: PHAge search tool; qPCR: Real time quantitative PCR; R-M system: Restriction-modification system; SRP: Signal recognition particle; T4SS: Type IV secretion system; TAL: Transcription activator-like

\section{Acknowledgements}

We thank two members of the Institute of Medical Microbiology and Hospital Hygiene, Dana Belick for excellent technical assistance, and Malte Kohns Vasconcelos for statistical support. Computational support and infrastructure were provided by the "Centre for Information and Media Technology" (ZIM) at the University of Duesseldorf (Germany).

\section{Authors' contributions}

$\mathrm{SH}$ and DH performed the PCR-based screening of $M$. hominis strains for ICEHo prevalence; UF, PLF and JS isolated and characterised some of the pathogenic clinical strains of M. hominis. KK, SS, LP and ATD performed NGS sequencing and bioinformatics analyses; $\mathrm{BH}, \mathrm{ATD}$ and KP defined the study design; $\mathrm{BH}$ and $\mathrm{AD}$ were major contributors in writing the manuscript. All authors read and approved the final manuscript.

\section{Funding}

This work was supported by the Jürgen Manchot Foundation and departmental funds from the Institute of Medical Microbiology and Hospital Hygiene, Heinrich-Heine-University of Duesseldorf, Germany. Open Access funding enabled and organized by Projekt DEAL.

\section{Availability of data and materials}

Genome sequences of strains LBD-4 (acc.-no. CP009652.1), PG21 (acc.-no. FP236530.1), SPROTT (acc.-no. CP011538.1), TO0613 (acc.-no: CP033021.1) and contigs of strain PL5 (acc.-nos: JRXA01000001.1 - JRXA010000016.1) were downloaded from NCBI (https://www.ncbi.nlm.nih.gov/nuccore/).

All raw sequencing data and high-quality assemblies are made available under BioProject PRJNA429440; all draft assemblies are available at OSF (DOI: 
https://doi.org/10.17605/OSF.IO/CZRBT). Generated genome sequences in FASTA format are available at NCBI. Generated genome sequences in GenBank format and annotated using this publication's annotation terminology are provided as an Additional file 7.

\section{Ethics approval and consent to participate}

The study was approved by the Ethical Committee of the Medical Faculty of the Heinrich-Heine University (Study-No.: 018-98-RetroDEuA). Consent to participate is not applicable due to the retrospective analysis of $\mathrm{M}$. hominis strains.

\section{Consent for publication}

Not applicable.

\section{Competing interests}

Not applicable.

\section{Author details}

${ }^{1}$ Institute of Med. Microbiology and Hospital Hygiene of the Heinrich-Heine-University Duesseldorf, Duesseldorf, Germany. ${ }^{2}$ Department of Haematology, Oncology and Clinical Immunology, Medical Faculty, University of Duesseldorf, Duesseldorf, Germany. ${ }^{3}$ Institute for Specific Prophylaxis and Tropical Medicine, Centre for Pathophysiology, Immunology and Infectiology, Medical University of Vienna, Vienna, Austria. ${ }^{4}$ Biological and Medical Research Centre (BMFZ) of the Heinrich-Heine-University Duesseldorf, Duesseldorf, Germany. ${ }^{5}$ Department of Biomedical Sciences, University of Sassari, Sassari, Italy. ${ }^{6}$ Institute of Microbiology, University of Veterinary Medicine Vienna, Vienna, Austria. ${ }^{7}$ Institute of Medical Statistics and Computational Biology, University of Cologne, Cologne, Germany. ${ }^{8}$ Cologne Excellence Cluster on Cellular Stress Responses in Aging-Associated Diseases (CECAD), University of Cologne, Cologne, Germany.

Received: 29 May 2020 Accepted: 22 October 2020 Published online: 07 November 2020

\section{References}

1. Taylor-Robinson D, Furr PM. Genital mycoplasma infections. Wien Klin Wochenschr. 1997;109:578-83.

2. Xiang L, Lu B. Infection due to mycoplasma hominis after left hip replacement: case report and literature review. BMC Infect Dis. 2019;19:50.

3. Waites KB, Katz B, Schelonka RL. Mycoplasmas and ureaplasmas as neonatal pathogens. Clin Microbiol Rev. 2005;18:757-89.

4. Goret J, Beven L, Faustin B, Contin-Bordes C, Le Roy C, Claverol S, Renaudin $\mathrm{H}$, Bebear C, Pereyre S. Interaction of mycoplasma hominis PG21 with human dendritic cells: Interleukin-23-inducing Mycoplasmal lipoproteins and Inflammasome activation of the cell. J Bacteriol. 2017;199:e00213-17.

5. Goret J, Le Roy C, Touati A, Mesureur J, Renaudin H, Claverol S, Bebear C, Beven L, Pereyre S. Surface lipoproteome of mycoplasma hominis PG21 and differential expression after contact with human dendritic cells. Future Microbiol. 2016;11:179-94.

6. Stalberg C, Noda N, Polettini J, Jacobsson B, Menon R. Anti-inflammatory Elafin in human fetal membranes. J Perinat Med. 2017:45:237-44.

7. Rappelli P, Carta F, Delogu G, Addis MF, Dessi D, Cappuccinelli P, Fiori PL. Mycoplasma hominis and Trichomonas vaginalis symbiosis: multiplicity of infection and transmissibility of M. hominis to human cells. Arch Microbiol. 2001;175:70-4

8. Cacciotto C, Dessi D, Cubeddu T, Cocco AR, Pisano A, Tore G, Fiori PL, Rapelli P, Pittau M, Alberti A. MHO_0730 is a surface-exposed calciumdependent nuclease of mycoplasma hominis promoting neutrophils extracellular traps formation and escape. J Infect Dis. 2019. https://doi.org/ 10.1093/infdis/jiz406

9. Pekmezovic M, Mogavero S, Naglik JR, Hube B. Host-pathogen interactions during female genital tract infections. Trends Microbiol. 2019. https://doi. org/10.1016/j.tim.2019.07.006.

10. Hopfe M, Deenen R, Degrandi D, Kohrer K, Henrich B. Host cell responses to persistent mycoplasmas--different stages in infection of HeLa cells with mycoplasma hominis. Plos One. 2013;8:e54219.

11. Henrich B, Kretzmer F, Deenen R, Kohrer K. Validation of a novel mho microarray for a comprehensive characterisation of the mycoplasma hominis action in HeLa cell infection. Plos One. 2017;12:e0181383.
12. Calcutt MJ, Foecking MF. Analysis of the complete mycoplasma hominis LBD-4 genome sequence reveals strain-variable Prophage insertion and distinctive repeat-containing surface protein arrangements. Genome Announc. 2015;3:e01582-14.

13. Degrange S, Renaudin H, Charron A, Bebear C, Bebear CM. Tetracycline resistance in Ureaplasma spp. and mycoplasma hominis: prevalence in Bordeaux, France, from 1999 to 2002 and description of two tet(M)-positive isolates of M. hominis susceptible to tetracyclines. Antimicrob Agents Chemother. 2008;52:742-4.

14. Calcutt MJ, Foecking MF. An excision-competent and exogenous mosaic transposon harbors the tetM gene in multiple mycoplasma hominis lineages. Antimicrob Agents Chemother. 2015;59:6665-6.

15. Meygret A, Peuchant O, Dordet-Frisoni E, Sirand-Pugnet P, Citti C, Bebear C, Beven $L$, Pereyre S. High prevalence of integrative and conjugative elements encoding transcription activator-like effector repeats in mycoplasma hominis. Front Microbiol. 2019;10:2385.

16. Citti C, Baranowski E, Dordet-Frisoni E, Faucher M, Nouvel LX. Genomic Islands in mycoplasmas. Genes (Basel). 2020;11:836.

17. Koren S, Walenz BP, Berlin K, Miller JR, Bergman NH, Phillippy AM. Canu: scalable and accurate long-read assembly via adaptive k-mer weighting and repeat separation. Genome Res. 2017;27:722-36.

18. Chin CS, Alexander DH, Marks P, Klammer AA, Drake J, Heiner C, Clum A, Copeland A, Huddleston J, Eichler EE, Turner SW, Korlach J. Nonhybrid, finished microbial genome assemblies from long-read SMRT sequencing data. Nat Methods. 2013;10:563-9.

19. Pereyre $S$, Sirand-Pugnet $P$, Beven $L$, Charron $A$, Renaudin $H$, Barre A, Avenaud P, Jacob D, Couloux A, Barbe V, de Daruvar A, Blanchard A, Bebear C. Life on arginine for mycoplasma hominis: clues from its minimal genome and comparison with other human urogenital mycoplasmas. Plos Genet. 2009;5:e1000677.

20. Seemann T. Prokka: rapid prokaryotic genome annotation. Bioinformatics. 2014;30:2068-9.

21. Darling AE, Mau B, Perna NT. progressiveMauve: multiple genome alignment with gene gain, loss and rearrangement. Plos One. 2010;5:e11147.

22. Baranowski E, Dordet-Frisoni E, Sagne E, Hygonenq MC, Pretre G, Claverol S, Fernandez L, Nouvel LX, Citti C. The integrative conjugative element (ICE) of mycoplasma agalactiae: key elements involved in horizontal dissemination and influence of Coresident ICEs. MBio. 2018;9:e00873-18.

23. Calcutt MJ, Lavrrar JL, Wise KS. IS1630 of mycoplasma fermentans, a novel IS30type insertion element that targets and duplicates inverted repeats of variable length and sequence during insertion. J Bacteriol. 1999;181:7597-607.

24. Murdoch DA. Gram-positive anaerobic cocci. Clin Microbiol Rev. 1998;11:81-120.

25. Ayling RD, Bashiruddin S, Davison NJ, Foster G, Dagleish MP, Nicholas RA. The occurrence of mycoplasma phocicerebrale, mycoplasma phocidae, and mycoplasma phocirhinis in grey and common seals (Halichoerus grypus and Phoca vitulina) in the United Kingdom. J Wildl Dis. 2011;47:471-5.

26. Grozner D, Forro B, Sulyok KM, Marton S, Kreizinger Z, Banyai K, Gyuranecz M. Complete genome sequences of mycoplasma anatis, M. anseris, and M. cloacale type strains. Microbiol Resour Announc. 2018;7:e00939-18.

27. Chang C-T, Tsai C-N, Tang CY, Chen C-H, Lian J-H, Hu C-Y, Tsai C-L, Chao A, Lai C-H, Wang T-H, Lee Y-S. Mixed sequence reader: a program for analyzing DNA sequences with Heterozygous Base calling. Sci World J. 2012 2012:365104.

28. Tardy F, Mick V, Dordet-Frisoni E, Marenda MS, Sirand-Pugnet P, Blanchard A, Citti C. Integrative conjugative elements are widespread in field isolates of mycoplasma species pathogenic for ruminants. Appl Environ Microbiol. 2015:81:1634-43.

29. Citti C, Dordet-Frisoni E, Nouvel LX, Kuo CH, Baranowski E. Horizontal gene transfers in mycoplasmas (Mollicutes). Curr Issues Mol Biol. 2018;29:3-22.

30. Cabezon E, Ripoll-Rozada J, Pena A, de la Cruz F, Arechaga I. Towards an integrated model of bacterial conjugation. FEMS Microbiol Rev. 2015;39:81-95.

31. Johnson CM, Grossman AD. Integrative and conjugative elements (ICEs): what they do and how they work. Annu Rev Genet. 2015:49:577-601.

32. Leanza AG, Matteo MJ, Crespo O, Antelo P, Olmos J, Catalano M. Genetic characterisation of helicobacter pylori isolates from an Argentinean adult population based on cag pathogenicity island right-end motifs, IspA-glmM polymorphism and iceA and vacA genotypes. Clin Microbiol Infect. 2004;10: 811-9.

33. Szuplewska M, Czarnecki J, Bartosik D. Autonomous and non-autonomous Tn3-family transposons and their role in the evolution of mobile genetic elements. Mob Genet Elements. 2014;4:1-4. 
34. MacKenzie CR, Nischik N, Kram R, Krauspe R, Jager M, Henrich B. Fatal outcome of a disseminated dual infection with drug-resistant mycoplasma hominis and Ureaplasma parvum originating from a septic arthritis in an immunocompromised patient. Int J Infect Dis. 2010;14(Suppl 3):e307-9.

35. Fichorova R, Fraga J, Rappelli P, Fiori PL. Trichomonas vaginalis infection in symbiosis with Trichomonasvirus and mycoplasma. Res Microbiol. 2017;168: 882-91.

36. Henrich B, Feldmann RC, Hadding U. Cytoadhesins of mycoplasma hominis. Infect Immun. 1993;61:2945-51.

37. Henrich B, Lang K, Kitzerow A, MacKenzie C, Hadding U. Truncation as a novel form of variation of the p50 gene in mycoplasma hominis. Microbiology. 1998;144(Pt 11):2979-85.

38. Loman NJ, Quick J, Simpson JT. A complete bacterial genome assembled de novo using only nanopore sequencing data. Nat Methods. 2015;12:733-5.

39. Walker BJ, Abeel T, Shea T, Priest M, Abouelliel A, Sakthikumar S, Cuomo CA Zeng Q, Wortman J, Young SK, Earl AM. Pilon: an integrated tool for comprehensive microbial variant detection and genome assembly improvement. Plos One. 2014;9:e112963.

40. DePristo MA, Banks E, Poplin R, Garimella KV, Maguire JR, Hartl C, Philippakis AA, del Angel G, Rivas MA, Hanna M, McKenna A, Fennell TJ, Kernytsky AM, Sivachenko AY, Cibulskis K, Gabriel SB, Altshuler D, Daly MJ. A framework for variation discovery and genotyping using next-generation DNA sequencing data. Nat Genet. 2011;43:491-8

41. Li H, Handsaker B, Wysoker A, Fennell T, Ruan J, Homer N, Marth G, Abecasis G, Durbin R, Genome Project Data Processing S. The sequence alignment/ map format and SAMtools. Bioinformatics. 2009;25:2078-9.

42. Li H. Aligning sequence reads, clone sequences and assembly contigs with BWA-MEM. ArXiv e-prints. arXiv. 2013;1303.3997.

43. Kurtz S, Phillippy A, Delcher AL, Smoot M, Shumway M, Antonescu C, Salzberg SL. Versatile and open software for comparing large genomes. Genome Biol. 2004:5:R12.

44. Robinson JT, Thorvaldsdottir H, Winckler W, Guttman M, Lander ES, Getz G, Mesirov JP. Integrative genomics viewer. Nat Biotechnol. 2011:29:24-6.

45. Hopfe M, Hegemann JH, Henrich B. HinT proteins and their putative interaction partners in Mollicutes and Chlamydiaceae. BMC Microbiol. 2005; 5:27.

46. Pfaffl MW. A new mathematical model for relative quantification in real-time RT-PCR. Nucleic Acids Res. 2001;29:e45.

47. Zhou Y, Liang Y, Lynch KH, Dennis JJ, Wishart DS. PHAST: a fast phage search tool. Nucleic Acids Res. 2011;39:W347-52.

48. Kelley LA, Mezulis S, Yates CM, Wass MN, Sternberg MJ. The Phyre2 web portal for protein modeling, prediction and analysis. Nat Protoc. 2015;10: 845-58.

49. Madeira F, Ym P, Lee J, Buso N, Gur T, Madhusoodanan N, Basutkar P, Tivey ARN, Potter SC, Finn RD, Lopez R. The EMBL-EBI search and sequence analysis tools APIs in 2019. Nucleic Acids Res. 2019;47:W636-41.

50. Bailey TL, Boden M, Buske FA, Frith M, Grant CE, Clementi L, Ren J, Li WW, Noble WS. MEME SUITE: tools for motif discovery and searching. Nucleic Acids Res. 2009;37:W202-8

\section{Publisher's Note}

Springer Nature remains neutral with regard to jurisdictional claims in published maps and institutional affiliations.

Ready to submit your research? Choose BMC and benefit from:

- fast, convenient online submission

- thorough peer review by experienced researchers in your field

- rapid publication on acceptance

- support for research data, including large and complex data types

- gold Open Access which fosters wider collaboration and increased citations

- maximum visibility for your research: over $100 \mathrm{M}$ website views per year

At $\mathrm{BMC}$, research is always in progress.

Learn more biomedcentral.com/submissions 